\title{
Optimization of heat transfer in the finite element process modelling of inertia friction welding of SCMV and AerMet 100
}

\author{
M. B. Mohammed, C. J. Bennett, P. H. Shipway \& T. H. Hyde \\ Department of Mechanical, Materials, and Manufacturing Engineering, \\ University of Nottingham, UK
}

\begin{abstract}
Inertia friction welding is the process in which stored kinetic energy in a flywheel is converted to heat by relative sliding movement between the components' surfaces. The process is widely used in joining high strength aero-engine alloys. Heat transfer interactions play a fundamental role in determining weld quality as temperature has a significant impact on the mechanical, thermal and metallurgical behaviours of materials. Heating and cooling rates influence thermal stresses induced by variations in material properties due to variations in temperatures. Heat transfer modes involved in the IFW process, apart from conduction, were hardly mentioned in previous work while their significance has not been identified. In this paper the heat transfer modes and their significance in the modelling of the IFW process of the high strength steels SCMV and AerMet 100 has been identified and a methodology by which experimental, numerical and empirical approaches were collectively utilised to optimize the heat transfer analysis is presented. The methodology was validated for optimizing the heat transfer analysis of the IFW process of the high strength steels that are the subject of this study.
\end{abstract}

Keywords: inertia friction welding, SCMV emissivity, AerMet100 emissivity, convection heat transfer coefficient, interface heat transfer coefficient.

\section{Nomenclature}

$A_{s} \quad$ surface area, $\mathrm{m}^{2}$

$a, b$ constants in eqn (6)

$z \quad$ cylinder length, $\mathrm{m}$

$\xi \quad$ emissivity 


\begin{tabular}{|c|c|c|c|}
\hline $\begin{array}{l}C \\
D\end{array}$ & specific heat capacity, $\mathrm{kJ} \mathrm{kg}^{-1} \mathrm{~K}^{-1}$ & $\sigma$ & $\begin{array}{l}\text { Stefan-Boltzmann constant } \\
567 \mathrm{E}-08 \mathrm{~W} \mathrm{~m}^{-2} \mathrm{~K}^{-4}\end{array}$ \\
\hline$d$ & diameter, $\mathrm{m}$ & $\theta$ & inclination angle, deg or ${ }^{\circ}$ \\
\hline $\begin{array}{l}h \\
k\end{array}$ & $\begin{array}{l}\text { heat transfer coefficient, } \mathrm{W} \mathrm{m}^{-2} \mathrm{~K}^{-1} \\
\text { thermal conductivity, } \mathrm{W} \mathrm{m} \mathrm{m}^{-1} \mathrm{~K}^{-1}\end{array}$ & $\infty$ & surrounding environment \\
\hline$m$ & mass, $\mathrm{kg}$ & \multicolumn{2}{|c|}{ Abbreviations } \\
\hline$N u$ & Nusselt number & $\operatorname{cln} d r$ & cylinder \\
\hline $\operatorname{Pr}$ & Prandtl number & cond & conduction \\
\hline$q$ & heat transfer rate, $\mathrm{W}$ & $\operatorname{conv}$ & convection \\
\hline$R a$ & Raleigh number & fld & fluid \\
\hline$r$ & cylinder radius, $\mathrm{m}$ & $m t r l$ & material \\
\hline$s$ & surface & rad & radiation \\
\hline$S h$ & Sherwood number & smpl & sample \\
\hline$T$ & temperature, $\mathrm{K}$ & tcw & thermocouple wires \\
\hline . & time, second & $W, D$ & workpiece-die \\
\hline
\end{tabular}

\section{Introduction}

Inertia friction welding (IFW) is a solid-state joining process. Prior to the start of welding, one of the workpieces is attached to a flywheel that is rotated to a specified speed in order to store a preset amount of kinetic energy, which is required to achieve the weld. The drive is then disengaged and the other workpiece is brought into contact with the rotating one under a constant axial force. This results in an increase in temperature at the mating surfaces due to friction. Once temperatures are sufficient to soften the material, axial shortening (upset) commences and material is expelled. The axial force is maintained after the flywheel comes to rest, allowing the metals to form a metallurgical bond [1].

Heat generation during the IFW process is dominated to a large extend by plastic deformation and frictional work which has been discussed previously by Mohammed et al. [2]. On the other hand, heat transfer (HT) from workpieces involves conduction, convection, radiation and HT across the workpiece-die contact interface. HT by conduction within workpieces was considered in all previous finite element (FE) models developed for modelling the IFW process [2-9] where it is treated as 2D conduction problem in a radial system (eqn (1)). However the few that considered the remaining HT modes expressed contradicting opinions regarding their importance while there was no mention of values and methods implemented to account for it. HT by Convection (eqn (2)) and radiation (eqn (3)) was neglected by $\mathrm{Fu}$ et al. [6] claiming that their effects are not significant as the total welding time is very short and contacting surfaces are not exposed to the surroundings; whereas Lee et al. [3] stated the opposite and considered both. It was only Moal and Massoni [4] who considered the HT across workpiece-die interface (eqn (4)).

$$
\begin{aligned}
& q_{\text {cond }}=\left[\frac{1}{r} \frac{\partial}{\partial r}\left(r \cdot k_{m t r l} \frac{d T}{d r}\right)+\frac{\partial}{\partial Z}\left(k_{m t r l} \frac{d T}{d z}\right)\right] \\
& q_{\text {conv }}=h_{\text {conv }} \cdot A_{s}\left(\begin{array}{ll}
T_{s} & T_{\infty}
\end{array}\right)
\end{aligned}
$$




$$
\begin{aligned}
& q_{\text {rad }}=\zeta \cdot \sigma \cdot A_{s}\left(\begin{array}{ll}
T_{s}^{4} & T_{\infty}^{4}
\end{array}\right) \\
& q_{W, D}=h_{W, D} \cdot A_{s}\left(T_{s}-T_{D}\right)
\end{aligned}
$$

Temperature has a significant impact on the mechanical, thermal and metallurgical behaviours of materials and heating and cooling rates influence thermal stresses induced by variations in material properties which are caused by variations in temperature. Therefore HT interactions during the IFW process directly impacts the residual stresses present at the joint and the regions around it which characterise the weld quality; hence the functionality of the welded component. In this paper the HT modes and their significance in the modelling of the IFW process of the high strength steels SCMV to AerMet 100 has been defined. A methodology by which experimental, numerical and empirical approaches are collectively utilised to determine the importance of and optimize the relative contributions of the HT modes is presented. The methodology had been validated for optimizing the HT analysis of the IFW process of the high strength steels which are the subject of this study. Weld parameters, materials properties, geometries, upset and temperatures are categorised as confidential information by Rolls-Royce plc and therefore will not be provided in this paper. Values are not given in some figures for the same reason.

\section{Numerical model description}

A coupled thermo-mechanical FE model was developed in this study using the commercial FE code DEFORM-2D. The code implements the minimum work rate principle and energy balance formulations to solve mechanical and thermal analysis, respectively Lee et al. [3]. The tubular workpieces, the dies transmitting flywheel rotation and axial force are represented by a 2D axisymmetric model with four-node isoparametric elements (Figure 1). Sticking was defined at the workpiece-die contact interface which allows relevant movements and forces to be transferred to relevant workpieces. Coulomb friction is defined as the coupling criteria at the contact interface between the workpieces. Conduction within workpieces, convection and radiation with environment and HT across the workpiece-die contact interface are included in the HT analysis. Mechanical and thermal material properties of both steels were prescribed to the relevant workpieces.

The modelling approach adopted is a combination of the representative models described in the work of Wang et al. [8] and Bennett et al. [9] where the weld energy is expressed by the recorded flywheel angular velocity run down as function of time [8] while frictional work was derived from the weld energy dissipation rate as in the work of Bennett et al. [9]. Simulation was carried out in four stages to recreate the weld scenario. Firstly is the welding stage where flywheel energy is being inputted into the weld indicated by the start and stop of the flywheel rotation. The second stage involves the cooling down of the stationary workpieces while the axial force is still applied. In the third stage the 


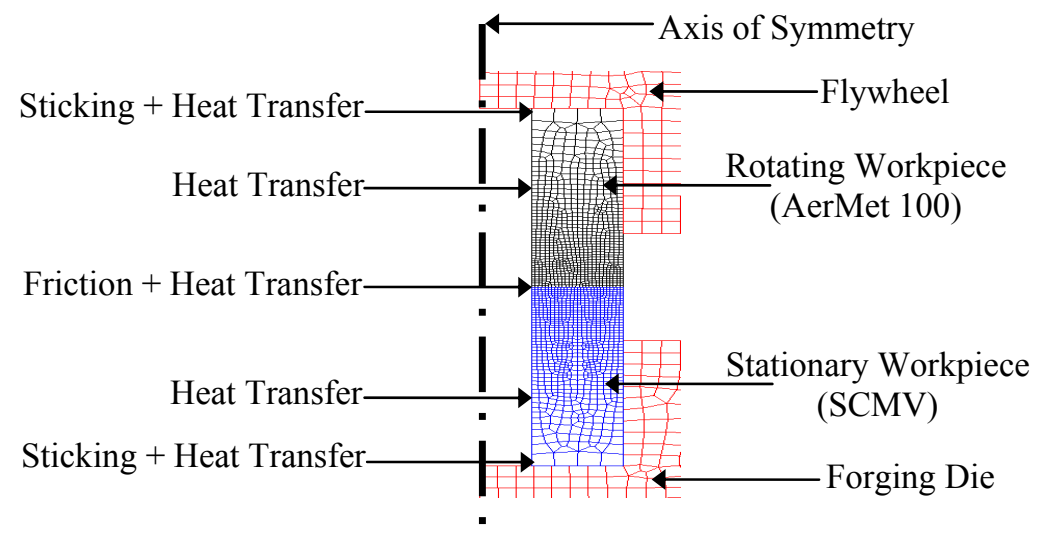

Figure 1: $\quad$ IFW process representation in the FE model.

axial load is removed while workpieces are still clamped, i.e. workpieces are in thermal contact with the dies and finally the workpieces are unclamped in the fourth stage.

\section{Sensitivity study}

A sensitivity study was initially carried out to identify the significance of HT modes in IFW process. Six models with various HT scenarios were investigated as detailed in Table 1. In these models the heat transfer coefficient (HTC) at the workpieces-dies interface, convection HTC and emissivity material property value are taken as the DEFORM recommended values, these being 11,000 $\mathrm{W} / \mathrm{m}^{2} \cdot \mathrm{K}, 20 \mathrm{~W} / \mathrm{m}^{2} \cdot \mathrm{K}$ and 0.7 respectively. The fact that the upset predicted by all six models is in very good agreement with the upset recorded during the welding process as shown in Figure 2 validates the combined representative modelling approach considered in this study.

The predicted temperature-time histories for a point positioned $5 \mathrm{~mm}$ away from the initial contact interface and at the centre of the wall thickness of the stationary workpiece were tracked for all modelling stages. During the welding stage (Figure 3), transient conditions are identical for all models indicating that thermal interactions during this stage are mainly dominated by conduction within the workpieces. This is because the temperature gradient within the workpieces is large enough to overshadow the temperature difference between workpieces and surrounding environment/dies. In fact, conduction remains as the dominant heat transfer mode even during the initial phase of the cooling evident by the identical temperature-time trends displayed by all models down to approximately $750^{\circ} \mathrm{C}$ (Figure 4). The significance of HT across workpiece-die interface is clearly evident by the rapid cooling that occurs in model-2 and model- 6 . 
Table 1: $\quad$ Heat transfer scenarios in the sensitivity study models.

\begin{tabular}{|c|c|c|c|c|}
\cline { 2 - 5 } \multicolumn{1}{c|}{} & \multicolumn{4}{c|}{ Heat Transfer Mode Considered } \\
\hline Model № & Conduction & Convection & Radiation & Workpiece-Die \\
\hline 1 & $\sqrt{ }$ & - & - & - \\
2 & $\sqrt{ }$ & - & - & $\sqrt{ }$ \\
3 & $\sqrt{ }$ & $\sqrt{ }$ & - & - \\
4 & $\sqrt{ }$ & - & $\sqrt{ }$ & - \\
5 & $\sqrt{ }$ & $\sqrt{ }$ & $\sqrt{ }$ & $\sqrt{ }$ \\
6 & $\sqrt{ }$ & $\sqrt{ }$ & & \\
\hline
\end{tabular}

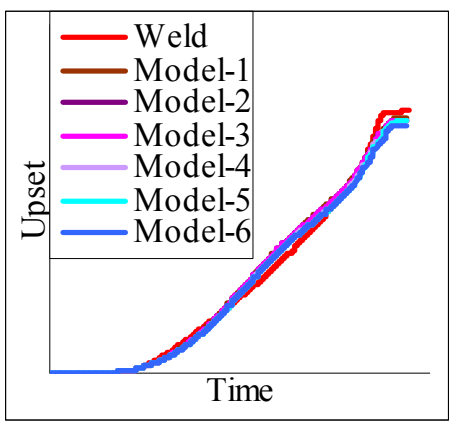

Figure 2: Comparison of FE Figure 3: Temperature-time history models upset with weld upset.

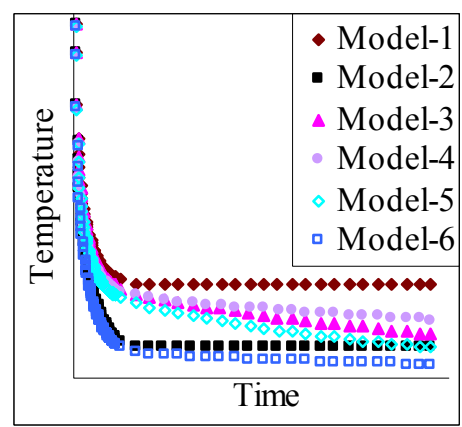

Figure 4: Temperature-time history during the cooling stage.

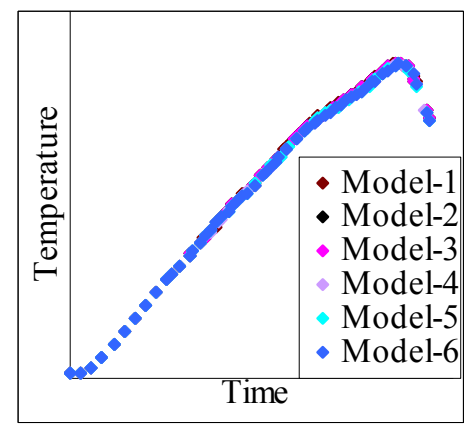
during the welding stage.

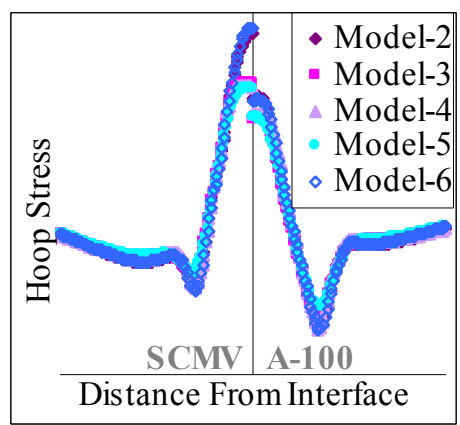

Figure 5: Hoop residual stress across workpieces wall thickness. 
The effect of the resulting various cooling rates experienced by the workpieces on residual stress predictions was examined for all models. The predicted residual stress profile along the mid-wall thickness location of both workpieces at room temperature is shown in Figure 5. It can be seen that much greater residual stresses are predicted for models with higher cooling rates. This is because higher cooling rates generate steeper temperature gradients, i.e. larger temperature variations, over a narrower region. As a result the stress induced by the cooler regions, whether it is expanding or contracting, on the neighbouring hotter regions is much greater than in the case of lower cooling rates where temperature gradients approach uniformity.

From the sensitivity study above it can be concluded that conduction is the dominant HT mode during the welding stage and the inclusion of the other HT modes does not significantly alter model predictions during this stage. However, during the cooling stage all HT modes influence temperature values and profiles and therefore cooling rates; whereas it is the HT across the workpiece-die interface that has the most significant impact during this stage. Most importantly residual stress predictions vary with cooling rates indicating that it is therefore essential to optimize the contribution of the HT modes to improve the reliability of model predictions.

\section{Heat transfer analysis optimization}

While the use of recommended HTCs in the sensitivity study assists in pointing out the significance of individual HT modes, it does not represent their physical behaviours. In the following, a generic methodology by which experimental, numerical and empirical approaches are collectively utilised to optimize the HT is presented. In this approach cooling curves for vertically suspended SCMV and AerMet 100 thin circular discs were generated experimentally where cooling is only due to convection and radiation. The experiments aimed to:

i. Quantify emissivity values for both steels.

ii. Ensure that convection and radiation are well represented in FE model.

iii. Estimate the value of workpiece-die interface HTC numerically.

\subsection{Experimental apparatus}

Three disc specimens for each material were cut off by wire-erosion from bulk material in the pre-weld condition followed by successive mechanical polishing with 240 and $400 \mathrm{SiC}$ grit paper. The diameters, thicknesses and masses of the discs were then measured using a micrometer with $0.01 \mathrm{~mm}$ resolution and a weighting scale with $0.0001 \mathrm{~g}$ resolution as shown in Table 2 . Two R-type thermocouples were spot-welded on the discs centreline $2 \mathrm{~mm}$ from its edge (Figure 6) to record temperature-time histories with a time step of 0.002 second. Thermocouple wires were inserted into a ceramic insulating channel to ensure that they were only in contact at the disc surface and to minimise HT from the surface of the wires. Discs are then washed with methylated spirit followed by 
Table 2: $\quad$ Dimensions and mass of disc specimens.

\begin{tabular}{|c|c|c|c|c|}
\hline Material & $\begin{array}{c}\text { Disc } \\
\text { Number }\end{array}$ & $\begin{array}{c}\text { Disc Diameter } \\
(\mathrm{mm})\end{array}$ & $\begin{array}{c}\text { Disc thickness } \\
(\mathrm{mm})\end{array}$ & $\begin{array}{c}\text { Disc Mass } \\
(\mathrm{g})\end{array}$ \\
\hline & 1 & 14.98 & 0.38 & 0.5178 \\
SCMV & 2 & 14.98 & 0.39 & 0.5367 \\
& 3 & 14.98 & 0.38 & 0.5221 \\
\hline & 1 & 14.99 & 0.37 & 0.5231 \\
A-100 & 2 & 14.99 & 0.37 & 0.5194 \\
& 3 & 14.99 & 0.37 & 0.5147 \\
\hline
\end{tabular}

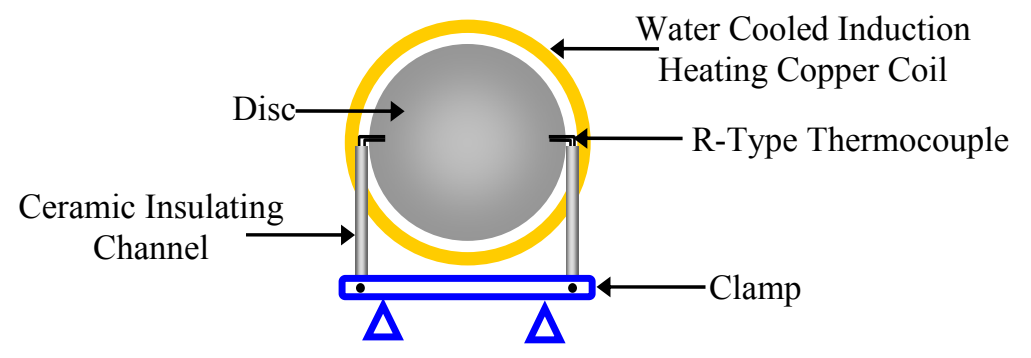

Figure 6: Disc cooling experimental apparatus.

blowing with compressed air to remove any foreign deposits. Discs were suspended vertically on the thermocouple wires and induction heated to just above $1100^{\circ} \mathrm{C}$ in an average time of about 35 seconds and then allowed to cool to ambient temperature of $24^{\circ} \mathrm{C}$.

\subsection{Emissivity calculations}

Emissivity calculations are based on the transient calorimetric technique for measuring surface emissivity of metals [10-12]. In this technique, samples are heated up to a temperature in a vacuum chamber and then allowed to cool down while recording the temperature-time histories. HT from the sample (eqn (5)) is due to convection, radiation and conduction along thermocouple wires. The cooling rate at any specific instant is obtained by expressing the temperaturetime history by an exponential function of the form of eqn (6) where the constants $a$ and $b$ are determined by using the least square method with a set of five adjacent experimental points as described in Masuda and Higano [10] and Tanda and Misale [12].

$$
\begin{gathered}
m \cdot C \cdot \frac{d T}{d t}=q_{\text {smpl }}=q_{\text {rad }}+q_{\text {conv }}+q_{t c w} \\
\frac{d T}{d t}=a \cdot \exp (-b \cdot t)
\end{gathered}
$$


The convection HTC for the disc samples is defined from the empirical correlations eqns (7) and (8) derived by Krysa et al. [13] with $\theta$ having a value of $0^{\circ}$ for the vertically suspended thin disc.

$$
\begin{gathered}
S h=\frac{h_{\text {conv }} \cdot d_{\text {smpl }}}{k_{f l d}} \\
S h=\left\{\left[0.622-\left(\frac{0.339}{50} \cdot \theta\right)\right] \cdot(R a)^{\left[0.243+\left(7.33 \cdot 10^{-6} \cdot(\theta+30.91)^{2}\right)\right]}\right\}
\end{gathered}
$$

HT by conduction along the thermocouple lead wires is calculated by eqn (9) as described in Tanda and Misale [12] and Greene et al. [14] where the thermal conductivity properties of the $\mathrm{Pt}$ and $\mathrm{Pt}-13 \% \mathrm{Rh}$ lead wires were taken from Powell and Tye [15] and Gong and Hardy [16] respectively.

$$
q_{t c w}=-\left(\frac{\pi \cdot d_{t c w}^{2} \cdot k_{t c w}}{4} \cdot \frac{\partial T_{t c w}}{\partial z_{t c w}}\right)
$$

From the knowledge of terms above, the emissivity values can be calculated as per eqn (10).

$$
\zeta=\frac{\left(m \cdot C \cdot \frac{d T}{d t}\right)-q_{c o n v}-q_{t c w}}{A_{s} \cdot \sigma \cdot\left(T_{s}^{4}-T_{\infty}^{4}\right)}
$$

\subsubsection{Results}

Emissivity values for the three discs of SCMV and AerMet 100 are shown in Figure 7. Both materials show similar trends in emissivity values as a function of temperature. The trend shows moderately low emissivity values at the low

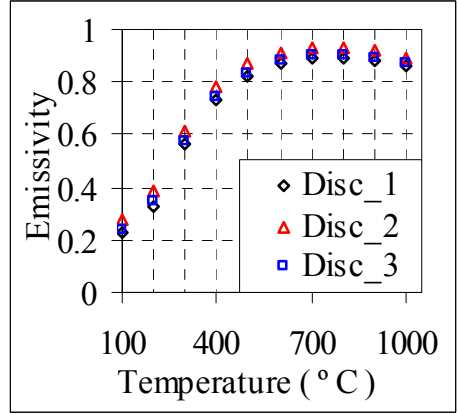

(a)

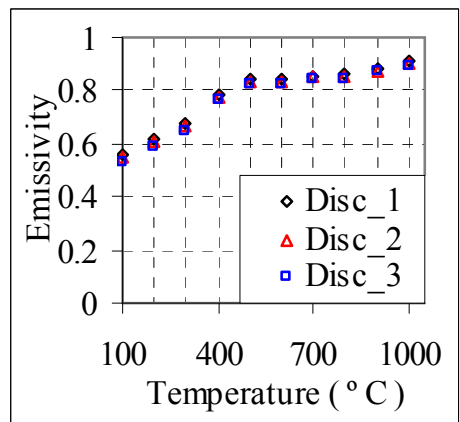

(b)

Figure 7: Emissivity values measured from cooling experiment; (a) SCMV, (b) AerMet 100. 
temperature range, $100-300^{\circ} \mathrm{C}$, and higher emissivity values at the high temperature range, $400-1000^{\circ} \mathrm{C}$. The drop in emissivity values in the low temperature range seem to be greater in SCMV. However emissivity values measured for both steels are within a range similar to those measured for similar materials Tanda and Misale [12] and Greene et al. [14].

\subsection{Modelling of cooling curve experiment}

The cooling experiment for both materials was recreated in FE models to examine whether the empirical correlations adopted to calculate the convection HTC and measured emissivity values were capable of offering good representation for the relevant HT modes. The thin circular discs were represented as an axisymmetric geometry while heat exchange with the surrounding environment by convection and radiation were defined as heat transfer boundary conditions (Figure 8). The initial temperature of discs is set to $1000^{\circ} \mathrm{C}$ where the surrounding environment temperature was set to $24^{\circ} \mathrm{C}$ as measured during the experiments. Another set of models with the recommended convection HTC and emissivity values were also examined.

Comparisons between the experimental results and models with both default HTCs and calculated HTCs are presented in Figure 9 for both materials. A faster cooling rate is predicted for both materials at temperatures below approximately $500^{\circ} \mathrm{C}$ when the recommended HTC values were used this was expected to occur as a constant value is used regardless of the disc surface temperature whereas both the convection HTC derived from the empirical correlation and the measured emissivity values drop at lower temperatures. It is however now evident that empirical correlations for convection HTC estimation and measured emissivity values offer a very good representation for convection and radiation HT behaviours.

\subsection{Numerical estimation of workpiece-die HTC}

The estimation of the workpiece-die interface HTC requires solving the thermal contact resistance problem which involves characterizing and studying complex physical interactions [17], whereas this value can be evaluated numerically as convection and radiation HT analysis are optimized. The numerical estimation takes the approach of carrying out a sensitivity study on the workpiece-die HTC value. The reference criteria for the sensitivity study are two points on the

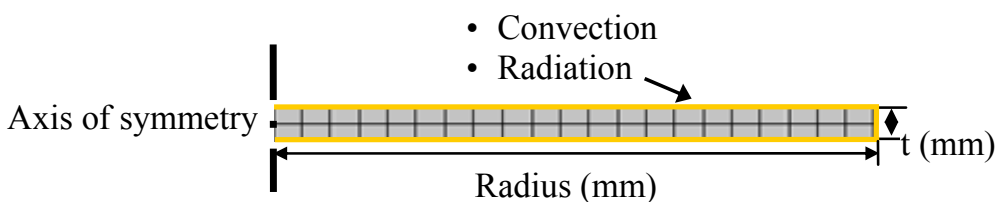

Figure 8: Cooling experiment representation in the FE model. 


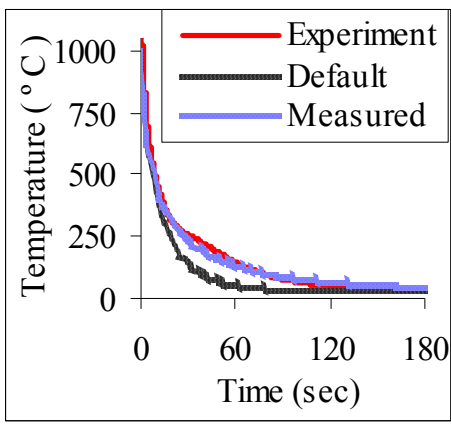

(a)

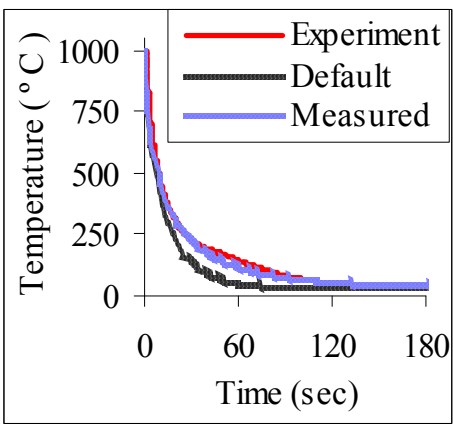

(b)

Figure 9: Comparison of experimental cooling of discs with FE models using default and measured HTC values; (a) SCMV, (b) AerMet 100.

temperature-time history recorded during the IFW process by two thermocouples placed along the length of the stationary workpiece at different locations. The temperatures associated with these points are 150 and $200^{\circ} \mathrm{C}$ for the thermocouples positioned far from and nearer to the weld interface, respectively.

The base FE model on which this numerical estimation was performed included all HT modes using emissivity values determined in Section 5.2.1 while convection HTCs were calculated using the empirical correlations (eqns (11) and (12)) developed by Churchill and Chu [18] for free convection from horizontal solid cylinders. The correlation is used based on the findings of the sensitivity study in section-4 which indicates that convection is only important during the cooling stage; here convection conditions involve natural cooling of the clamped welded workpieces. Convection HT is subject to the thermo-physical properties and flow conditions of the fluid in contact with the workpiece surface where the latter is influenced by the surface geometry (Incropera et al [19]). Therefore, convection HT from the horizontally clamped tubular workpieces can be best represented by the solid horizontal cylinder.

$$
\begin{gathered}
N u=\frac{h_{\text {conv }} \cdot d_{c \operatorname{lndr}}}{k_{f l d}} \\
N u=\left\{0.6+\frac{0.387 \cdot R a^{1 / 6}}{\left[1+(0.559 / \mathrm{Pr})^{9 / 16}\right]^{8 / 27}}\right\}
\end{gathered}
$$

The results of the sensitivity study varying the value of the workpiece-die HTC (Figure 10) indicate that this HTC value is within the range of 500-1000 $\mathrm{W} / \mathrm{m}^{2} . \mathrm{K}$ instead of the recommended value of $11,000 \mathrm{~W} / \mathrm{m}^{2} . \mathrm{K}$. It is decided to take the value of the workpiece-die interface HTC as the value that predicts a temperature similar to that was measured by the thermocouple positioned far from weld interface as it did not move from its initial position during the welding 


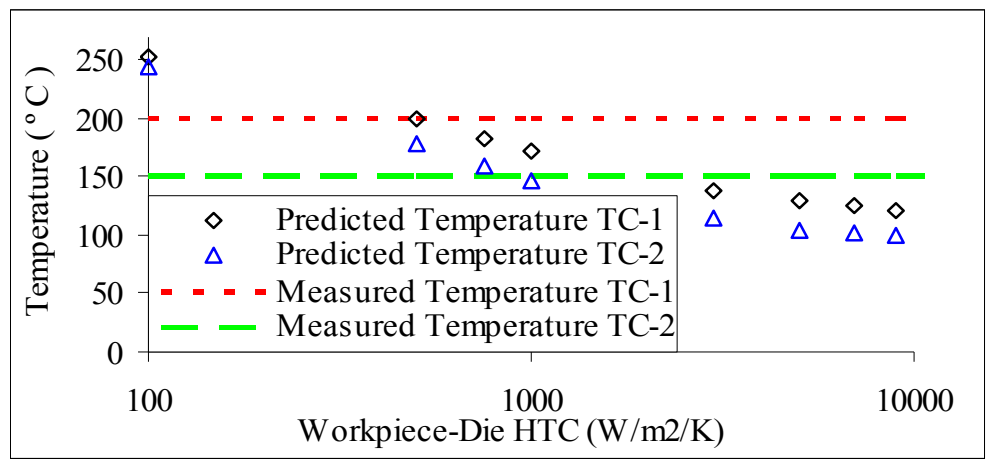

Figure 10: Numerical estimation of workpiece-die HTC.

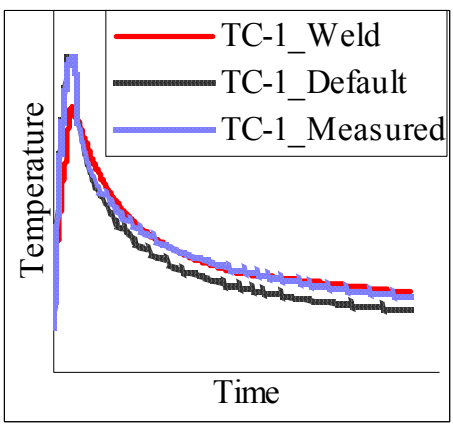

(a)

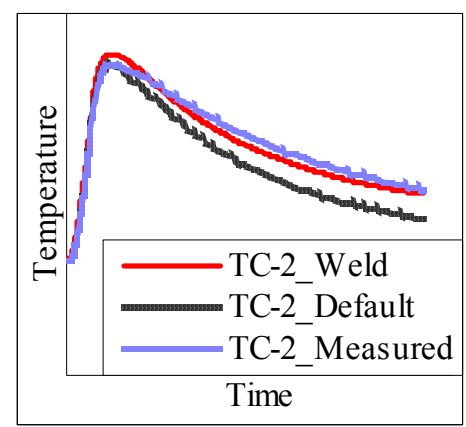

(b)

Figure 11: Comparison of recorded and predicted thermocouples temperaturetime history: (a) near weld interface; (b) far from weld interface.

process, this gives an HTC value for the contact of $1000 \mathrm{~W} / \mathrm{m}^{2} . \mathrm{K}$. The transient conditions predicted by the developed HTC values for both thermocouples are in very good agreement with those recorded during the welding process as shown in Figure 11.

\section{Conclusions}

The significance of heat transfer by conduction, convection, radiation and across the workpiece-die interface in the modelling of the IFW process of SCMV to AerMet-100 high strength steels was investigated via a numerical sensitivity study. It has been concluded from this study that conduction is the dominant heat transfer mode during the welding stage whereas the heat transfer across the workpiece-die contact interface that has the greatest impact during cooling.

A generic approach to optimize heat transfer analysis in the modelling of IFW processes has been developed and validated for the welding process subject of this study. In this approach it was found that empirical correlations are sufficient 
for estimating convection heat transfer. Experimental apparatus based on the transient calorimetric technique was developed to generate cooling curves for both steels under conditions that are representative of the IFW process. Emissivity values for both steels were measured and FE models were developed to ensure that convection and radiation heat transfer are well represented. Finally, it was possible to numerically estimate the workpiece-die interface HTC which was found to be approximately $1000 \mathrm{~W} / \mathrm{m}^{2} . \mathrm{K}$. The transient conditions predicted by using the adopted empirical correlation for convection HTC, the measured emissivity values and the numerically estimated workpiece-die HTC in the model were validated.

\section{Acknowledgement}

This work has been carried out under the PROMOTE project funded by The Technology Strategy Board. The Technology Strategy Board is a business-led executive non-departmental public body, established by the government. Its mission is to promote and support research into, and development and exploitation of, technology and innovation for the benefit of UK business, in order to increase economic growth and improve the quality of life. It is sponsored by the Department for Innovation, Universities and Skills (DIUS). Please visit www.innovateuk.org for further information.

\section{References}

[1] Roy, A., Norman, L. and Braton, R., Welding and Other Joining Processes, Allyn and Bacon Inc., 47-49, 1976.

[2] Mohammed, M.B., Bennett, C.J., Hyde, T.H. and Williams, E.J., The evaluation of coefficient of friction for representative and predictive finite element modelling of the inertia friction welding, ASME/IGTI, 2009.

[3] Lee, K., Samant, A. and Wu, W.T., Finite Element Modeling of Inertia Friction Welding Processes, 1988.

[4] Moal, A. and Massoni, E., Finite Element Simulation of the Inertia Friction Welding of Two Similar Parts, 12, 497-512, 1995.

[5] D'Alvise, L., Massoni, E. and Walloe, S.J., Finite Element Modelling of the Inertia Friction Welding Process Between Dissimilar Materials, 125, 387391, 2002.

[6] Fu, L., Duan, L.Y. and Du, S.G., Numerical Simulation of Inertia Friction Welding Process by Finite Element Method, 65-70, 2003.

[7] Liwen, Z., Chengdong, L., Shaoan, Q., Yongsi, Y., Wenhui, Z., Shen, Q. and Jinghe, W., Numerical Simulation of Inertia Friction Welding Process of GH4169 alloy, 120, 681-687, 2004.

[8] Wang, L., Preuss, M., Withers, P.J., Baxter, G. and Wilson, P., EnergyInput Based Finite Element Process Modelling of Inertia Welding, 36B, 513-523, 2005.

[9] Bennett, C.J., Hyde, T.H. and Williams, E.J., Modelling and Simulation of the Inertia Friction Welding of Shafts, 221, 275-283, 2007. 
[10] Masuda, H. and Higano, M., Transient calorimetric technique for measuring total hemispherical emissivities of metals with rigorous evaluation of heat loss through thermocouple leads, 2, 1877-1882, 1985.

[11] Butler, C.P. and Jenkins, R.J., Space chamber emittance measurements, NASA, 39-43, 1963.

[12] Tanda, G. and Misale, M., Measurement of total hemispherical emittance and specific heat of Aluminum and Inconel-718 by a calorimetric technique, 128, 302-306, 2006.

[13] Krysa, J., Reuter, W. and Wragg, A.A., Free convection mass transfer at circular thin disk electrodes with varying inclination, 48, 2323-2332, 2005.

[14] Greene, G.A., Finfrock, C.C. and Jr, T.F.I., Total hemispherical emissivity of oxidized Inconel-718 in the temperature range 300-1000C, 22, 145-153, 2000.

[15] Powell, R.W. and Tye, R.P., The promise of platinum as a high temperature thermal conductivity reference material, 14, 662-666, 1963.

[16] Gong, C. and Hardy, B.J., Thermal stress analysis of Am/Cm stabilization bushing melter, ASME, 12-31, 1997.

[17] Cooper, M.G., MIKIC, B.B. and Yovanovich, M.M., Thermal contact conductance, 12, 279-300, 1969.

[18] Churchill, S.W. and Chu, H.H.S., Correlation Equations for Laminar and Turbulent Free Convection from A Horizontal Cylinder, 18, 1049-1053, 1974.

[19] Incropera, F.P., Dewitt, D.P., Bergman, T.L. and Lavine, A.S., Introduction to Heat Transfer, John Wiley \& Sons, Inc, 901, 2007. 